\title{
The Dynamics of Endophytic Bacterial Community Structure in Rice Roots under Different Field Management Systems
}

\author{
Guan-Ying Lin ${ }^{1,2}$, Chia-Yu Lin ${ }^{3}$, Su-Jein Chang ${ }^{3}$ and Wei-Yi Lin ${ }^{1, *(1)}$ \\ 1 Department of Agronomy, National Taiwan University, Taipei 10617, Taiwan; louises@tfri.gov.tw \\ 2 Silviculture Division, Taiwan Forestry Research Institute, Taipei 10066, Taiwan \\ 3 Miaoli District Agricultural Research and Extension Station, Council of Agriculture, Gungguan, \\ Miaoli 36346, Taiwan; 328@mdais.gov.tw (C.-Y.L.); sujein@mdais.gov.tw (S.-J.C.) \\ * Correspondence: weiyilin@ntu.edu.tw
}

Received: 22 September 2020; Accepted: 20 October 2020; Published: 22 October 2020

\begin{abstract}
The structure of endophytic bacteria is important to plant health and stress tolerance, but little is known about the impacts of farming systems on temporal changes in diversity of endophytic bacteria. In this study, we investigated the endophytic microbiome in rice roots under organic and conventional farming systems at the seedling and tillering stages over two consecutive cropping seasons using $16 \mathrm{~S}$ rRNA gene sequencing. Although the composition of the microbiome was significantly influenced by a field management system, growth stage, and interaction between the two factors, the growth stage alone explained more than $40 \%$ of variance. Soil $\mathrm{pH}$ and organic matter content also partially influenced the endophytic bacterial community composition. In addition, through indicator species analysis and the functional profiles predicted by phylogenetic analysis, we revealed the selection force of rice roots at the tillering stage to recruit endophytes, which are beneficial to plant growth. In summary, our data show that the dynamics of rice root bacterial composition are mainly influenced by the plant growth stage. Our findings offer new insights regarding the control of the root microbiome by host plants and the influence of farming systems.
\end{abstract}

Keywords: endophytic bacterial microbiome; field management; growth stage

\section{Introduction}

The development of the conventional farming system, which relies heavily on chemical fertilizers and control agents, such as pesticides and herbicides, has helped double crop yields and improve food security in the past decades [1]. However, this system also has a high impact on agricultural and natural ecosystems [1-4]. Thus, the organic farming system, which has been practiced for thousands of years in human history, is once again attracting attention. This kind of field practice increases soil and water conservation and reduces greenhouse gas emissions, supporting ecosystems [4-6].

The effects of agricultural practices, such as fertilizer application and mowing frequency, as well as the cropping system on the soil, or rhizosphere, microbiome have been reported. Tillage strength and the management of crop residue significantly affect the composition of soil bacterial communities and, to a lesser extent, fungal communities [7-9]. The crop rotation system increases the sustainability of the agriculture ecosystem, and affects the composition of fungal communities more than the bacterial communities [10]. In addition, soil fungal communities are more sensitive to the cropping system than bacterial communities $[8,11,12]$. Plant endophytes are defined as microbes isolated or extracted from surface-sterilized tissue [13]. Of those microbes that do not cause visible harm, most are commensals but a few are mutualists and have positive effects on plant growth or stress tolerance [14]. Several mutualists 
are commercially produced and used in the agriculture system as biofertilizers or biocontrol agents. However, little is known about the response of plant endophytes to cropping systems. Xia et al. [15] isolated culturable endophytes from four crops either under conventional or organic farming systems and found that organic farming increased the abundance and diversity of endophytes. A later study provided supporting evidence regarding the higher $\alpha$-diversity of root bacterial communities under an organic farming system and the impact was more significant on endophytes than soil microbes [8]. Although endophytes are affected by agricultural practices, the effects vary by host plant species [16]. These observations suggest that mechanical practices that interfere with the structure of soil have a greater impact on soil microbes, while the field management practices that change soil properties influence endophyte communities.

It is believed that endophytic bacteria are derived from seeds, recruited from the rhizosphere or phylloplane, or disseminated from stomata and wounds and then colonize plant tissue [14,17-19]. Root exudates, including sugars, organic acids, fatty acids, and secondary metabolites, are attractants of microorganisms which support the diversity of the rhizosphere microbiome $[20,21]$. The composition of root exudates varies with environmental conditions, plant species, and plant growth stages [22-25], suggesting that the structure of microorganism communities in the rhizosphere also differs by these factors. The influence of plant growth stage on rhizosphere microbial communities has been reported in several plant species [26-28]. Chaparro et al. [29,30] and Zhalnina et al. [25] demonstrated the variation of metabolite preferences of microorganisms and dynamics of root exudate composition over the process of plant development, leading to modifications of the rhizosphere's microbial community structure over time. The effects of growth stage on root endophyte composition have been investigated using PCR-denaturing gradient gel electrophoresis and restriction fragment length polymorphism (RFLP) analysis of the 16S rRNA gene [27,31-34] however, due to the limited resolution of these techniques, a comprehensive analysis of the root endophyte microbiota is still required to unravel the detail of plant growth stage effects.

Evidence has revealed the benefits of endophytes and their versatile functions in crop production. To program and manage the endophytic microbiome, it is important to understand the influence of agricultural practices and growth stages on the endophyte community structure and diversity. In this study, we investigated the rice root endophytic bacterial microbiome either under conventional or organic farming systems at seedling and tillering stages by using $16 \mathrm{~S}$ rRNA gene sequencing over two consecutive cropping seasons. We hypothesized that without chemical disturbance, the diversity of root endophytes and beneficial bacterial communities would increase during rice plant growth.

\section{Materials and Methods}

\subsection{Experimental Sites}

The conventional and organic paddy fields were located in the town of Miaoli county, Taiwan. The soil texture of all the experimental sites are silty clay loam. Rice plants have been planted in these fields continuously for many years. The experiments were conducted over two consecutive cropping seasons in 2019. The monthly precipitation, temperature, and the cropping season are shown in Figure 1. Two conventional and two organic fields were included each season. The conventional fields sampled in both seasons were the same. But the organic fields sampled in the first season were left fallow in the following season. In the second cropping season, we sampled in another two organic fields in the same region. Information regarding the location of experimental fields, the rice cultivars used, sampling time, the total nitrogen input, fertilizer used, and organic farming history are listed in Table 1 and Table S1. In the conventional fields, chemical fertilizers and control reagents were used, while castor pomace and other commercial organic fertilizers were applied as a base and top dressing in organic fields. The total nitrogen input ranged from 126 to $231 \mathrm{~kg}$ per hectare in the first cropping season, and from 111 to $146 \mathrm{~kg}$ per hectare in the second season (Table S1). In the first and second cropping season, rice seedlings were transplanted in mid-February and early August, respectively. 


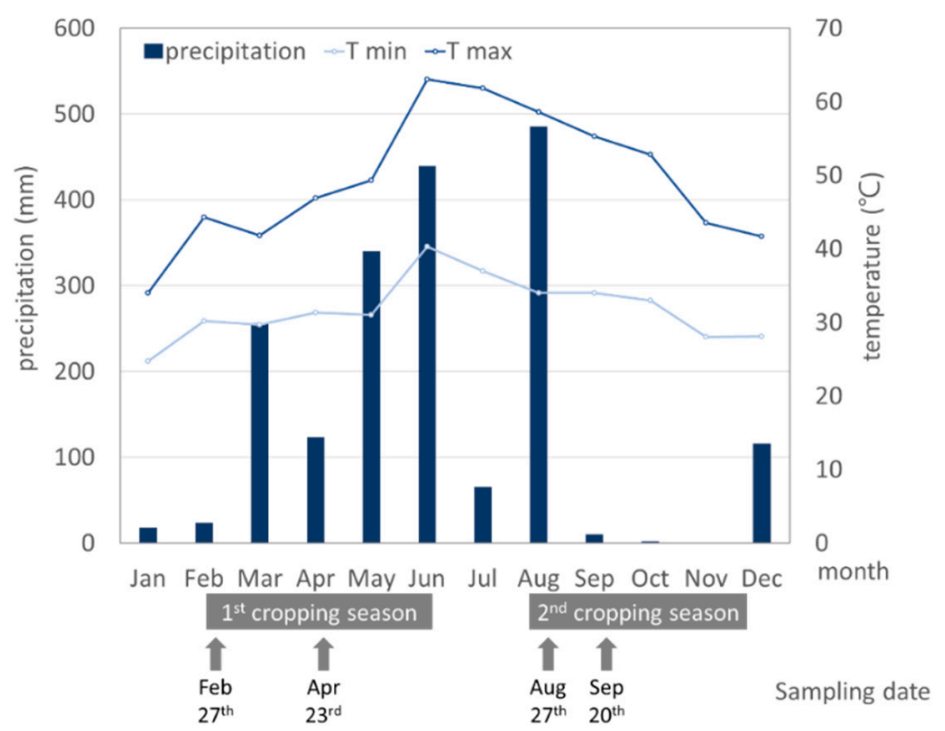

Figure 1. Monthly temperature and precipitation in 2019. The first cropping seasons was from mid-February to late June and the second season was from early August to late November. $\mathrm{T}$ min and $\mathrm{T}$ max are the monthly minimum and maximum temperature, respectively.

Table 1. Sampling sites and sample information.

\begin{tabular}{|c|c|c|c|c|}
\hline Cropping Season & Growth Stage & Management & Sample Name ${ }^{a}$ & Sampling Time ${ }^{b}$ \\
\hline \multirow{8}{*}{$\begin{array}{c}\text { First season } \\
2019\end{array}$} & \multirow{4}{*}{ Seedling } & \multirow{2}{*}{ Conventional } & C1Xie & $5 \mathrm{DAT}$ \\
\hline & & & C1Chiu & $10 \mathrm{DAT}$ \\
\hline & & \multirow{2}{*}{ Organic } & O1Liu & $7 \mathrm{DAT}$ \\
\hline & & & O1Xie & $5 \mathrm{DAT}$ \\
\hline & \multirow{4}{*}{ Tillering } & \multirow{2}{*}{ Conventional } & C1Xie_T & $60 \mathrm{DAT}$ \\
\hline & & & C1Chiu_T & 65 DAT \\
\hline & & \multirow{2}{*}{ Organic } & O1Liu_T & $62 \mathrm{DAT}$ \\
\hline & & & O1Xie_T & $60 \mathrm{DAT}$ \\
\hline \multirow{8}{*}{$\begin{array}{l}\text { Second season } \\
2019\end{array}$} & \multirow{4}{*}{ Seedling } & \multirow{2}{*}{ Conventional } & $\mathrm{C} 2 \mathrm{Xie}$ & $21 \mathrm{DAT}$ \\
\hline & & & C2Chiu & $28 \mathrm{DAT}$ \\
\hline & & \multirow{2}{*}{ Organic } & O2Shiu1 & $18 \mathrm{DAT}$ \\
\hline & & & O2Shiu2 & $18 \mathrm{DAT}$ \\
\hline & \multirow{4}{*}{ Tillering } & \multirow{2}{*}{ Conventional } & C2Xie_T & $46 \mathrm{DAT}$ \\
\hline & & & C2Chiu_T & $53 \mathrm{DAT}$ \\
\hline & & \multirow{2}{*}{ Organic } & O2Shiu1_T & 43 DAT \\
\hline & & & O2Shiu2_T & 43 DAT \\
\hline
\end{tabular}

a The sample name was given based on the field management, cropping season, and farmers' family name. $\mathrm{C}$ and $\mathrm{O}$ mean conventional and organic farming systems, respectively, and the following number indicates the cropping season. The last $\mathrm{T}$ in the sample name indicates that samples were harvested at the tillering stage. ${ }^{\mathrm{b}}$ DAT: Days after transplanting.

\subsection{Sample Collection and DNA Extraction}

In the first cropping season, rice plants were harvested at 5-10 days and 60-65 days after transplanting. In the second cropping season, seedlings were harvested two more weeks later than in the first season because of the time for finding another two organic fields, and tillering samples were harvested earlier due to the fast growing under high temperature in the beginning of the cropping 
season (Table 1 and Figure 1). Five healthy rice clumps were sampled randomly from each field. Rice roots were washed by tap water to remove soil. Subsequently, roots were surface sterilized with $1 \%$ sodium hydrochloride for $1 \mathrm{~min}$, followed by washing 5 times with sterile distilled water, and then blotted dry. The tissues were frozen by liquid nitrogen and stored at $-80^{\circ} \mathrm{C}$ until DNA extraction.

Microbial DNA was extracted using DNeasy ${ }^{\circledR}$ PowerSoil ${ }^{\circledR}$ Kit (Qiagen, Hilden, Germany) according to the manufacturer's instructions and was stored at $-80{ }^{\circ} \mathrm{C}$ for further experiments.

\section{3. $16 S$ rRNA Gene Library Preparation and Sequencing}

The V3-V4 highly variable region of $16 \mathrm{~S}$ rRNA genes in extracted DNA samples were amplified with primer set 319F (5'-CCTACGGGNGGCWGCAG-3') and 806R (5'-GACTACHVGGGTAT CTAATCC-3'). The amplicon library was attached by Illumina sequencing adaptors and then sequenced on an Illumina Miseq platform (Illumina, San Diego, CA, USA) performed by Biotools Co., Ltd. (Taipei, Taiwan). Paired-ended reads were generated and reads with low quality were filtered out in the QIIME (v1.9.1) pipeline before further analysis [35].

\subsection{Data Analysis}

Overlapping paired-end reads were assembled by FLASH (v1.2.11) [36]. Sequences with 97\% similarity were clustered into operational taxonomic units (OTUs) with UPARSE [37] in the USEARCH (v7.0.1090) pipeline [38]. The SILVA database (v132) was used for taxonomy assignment [39]. OTUs classified as mitochondria or chloroplasts were filtered out and the abundance was normalized by rarefying to the minimum sequence depth using QIIME (single_rarefication.py).

Alpha diversity ( $\alpha$-diversity) was estimated by QIIME to assess the complexity of species in samples using several indices, including observed species, Chao1, Shannon, Simpson, abundance-based coverage estimator (ACE), and phylogenetic diversity index (PD_whole_tree) [40]. Beta diversity ( $\beta$-diversity) analysis was conducted with Bray-Curtis distance matrices using QIIME and R script (v3.3.1). PERMANOVA was applied to evaluate the variance between data sets using the "adonis" function in R package "vegan" [41]. Principle component analysis (PCA) was performed on the relative abundance of filtered OTU tables by using the "factoextra" and "ggplot2" packages in the R software. A Mantel test was performed in the R package "vegan" using Bray-Curtis distance for all samples and Euclidean distance for environmental factors to evaluate the correlation between bacterial communities and environmental factors and this was further tested by Spearman correlation with 9999 permutations. Then, canonical correlation analysis (CCA) was employed to demonstrate the correlation using the "phyloseq" and "microbiome" packages in R.

To identify indicator species in response to growth stage or field management, function "multipatt" in the R "indispecies" package was performed to test the correlation between OTU abundance and these variables. Then, a likelihood ratio test was employed using the "glmLRT" function in $\mathrm{R}$ package "edgeR" to test the sensitivity of OTUs to the growth stage or field management.

For functional composition of metagenome data, PICRUSt (v1.1.1) [42] was performed based on the Greengenes phylogeny [43] and the function was classified using KEGG (Kyoto Encyclopedia of Genes and Genomes) Orthology [44]. A heatmap clustered by Euclidean distance was generated using the "ComplexHeatmap" package in $\mathrm{R}$ to show the strength of predicted gene functions.

\subsection{Statistic Analysis}

Statistical analysis was performed using $\mathrm{R}$ "stats" package (v4.0.2) and results were considered statistically significant at $p<0.05$. A Kruskal-Wallis test with Dunn's multiple comparison post hoc test was applied to evaluate the variance of $\alpha$-diversity indices between groups. The difference of bacterial abundance between groups was assessed by Welch's t test using STAMP (v2.1.3) [45]. 


\section{Results}

\subsection{The Influence of Field Management on Soil Property and Fertility}

In this study, each season the samples included four irrigated rice paddy fields, two of which were managed under a conventional farming system and two of which were managed under an organic farming system. All fields were cultivated with Japonica-type rice, although cultivars differed between fields (Table S1). The monthly rainfall and temperature analysis showed that the temperature gradually increased and decreased during the first and second cropping seasons, respectively. The rainfall was highest in August, when seedling samples were harvested in the second cropping season, and dramatically decreased when harvesting tillering samples. In contrast, the rainfall in the first season was higher at the tillering stage than the seedling stage (Figure 1). The soil pH and organic matter content in organic fields were higher than in conventional fields, but we did not observe consistent effects of field management on the value of soil electrical conductivity (EC); phosphorus (P) availability; the level of exchangeable potassium $(\mathrm{K})$, magnesium $(\mathrm{Mg})$, and calcium $(\mathrm{Ca})$; the percentage of $\mathrm{K}, \mathrm{Mg}$, and Ca saturation; or the ratio of $\mathrm{Mg}$ to $\mathrm{K}$ and $\mathrm{Ca}$ to $\mathrm{Mg}$ (Table S2).

\subsection{Analysis of Rice Root Endophytic Bacterial Profiles}

We analyzed the rice root endophytic bacterial profiles of rice plants sampled at the seedling and tillering stages from conventional and organic farming paddy fields to investigate the influence of field management and growth stage on bacterial diversity. We yielded a total of 1,219,439 and 2,335,249 high-quality sequences in the samples harvested in the first and second cropping season, respectively (Table S3), which were assigned to 2277 and 3286 OTUs, respectively. The average of Good's coverage was $96.5 \%$ (range 93.7-98.4\%) and 97.4\% (range 95.7-98.9\%) in the first and second cropping season, respectively (Table S3). The effect size between sample groups on bacterial composition were evaluated by using PERMANOVA. In both seasons, samples harvested from different types of field management were less similar than those from the same type, except the seedling samples harvested from organic fields in the first cropping season (Table S4).

The bacterial communities identified across all samples were classified into phylotype, consisting of Proteobacteria, Firmicutes, Bacteroidetes, Spirochaetes, Epsilonbacteraeota, Actinobacteria, Chloroflexi, Fibrobacteres, and other phyla which represented less than $1 \%$ abundance. In total, the relative abundance of three major phyla, Proteobacteria, Firmicutes, and Bacteroidetes, was over $73 \%$, but their abundance ratio varied by growth stage and cropping season. In the first cropping season, the relative abundance of Proteobacteria dramatically increased at the tillering stage compared to the seedling stage, while the opposite pattern was found for Firmicutes and Bacteroidetes (Figure 2A). In the second season, no significant difference was observed between growth stages (Figure 2B). When comparing the relative abundance of major phyla between two seasons, we found that Firmicutes was more abundant at the tillering stage in the second season than the first (Figure 2). These data suggest that the impacts of cropping season on root bacterial communities should be considered. 

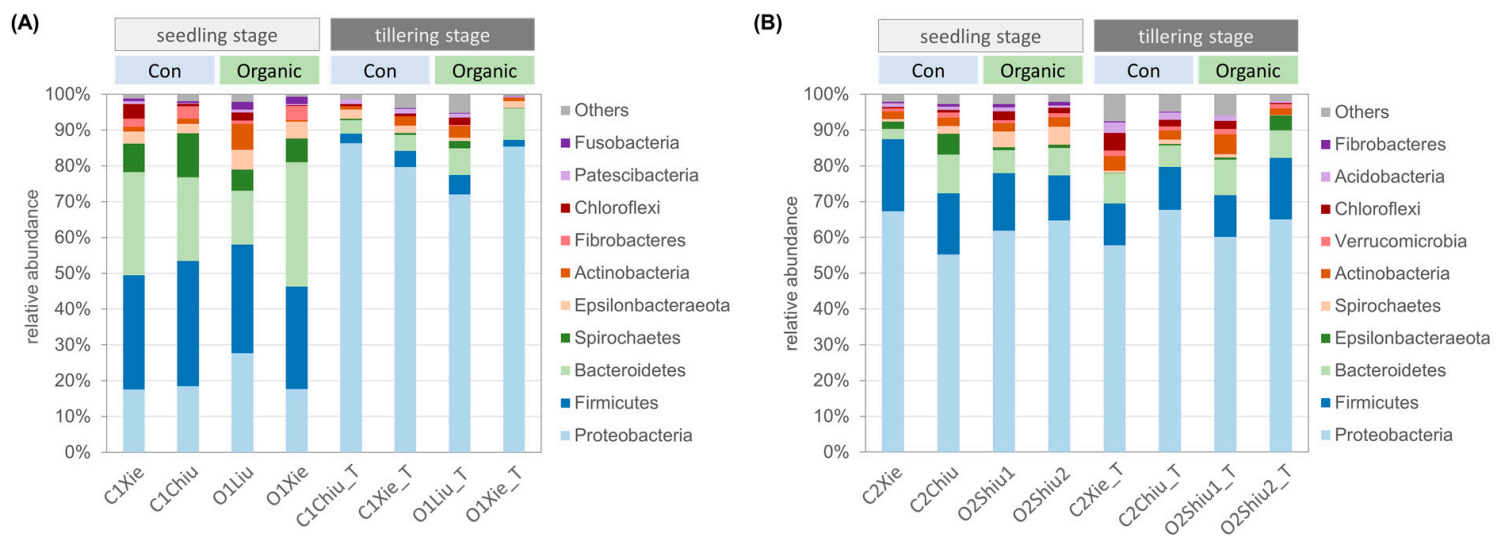

Figure 2. Relative abundance of the top 10 bacterial phyla in rice roots in the first (A) and second (B) cropping seasons. Con: Conventional farming system; Organic: Organic farming system.

\subsection{The Impacts of Soil Properties and Field Management on Root Microbial Diversity}

The difference of field management system resulted in a variation of soil $\mathrm{pH}$ and organic matter content. Whether these variables affected root microbial diversity was unclear. In order to address this question, first we estimated the $\alpha$-diversity indices, including observed species, Chao1, Shannon, Simpson, ACE, and "PD_whole_tree" to show the richness, diversity, and evenness of the bacterial communities. While there was a significant difference between samples, this was attributed to a location effect rather than the field management system (Table S5).

Next, we assessed the heterogeneity of the bacterial community composition across samples using $\beta$-diversity analysis based on Bray-Curtis distance. Although the field management system did not affect species diversity and richness, PERANOVA showed that it did influence the endophytic bacterial profile in both cropping seasons, especially at the tillering stage (Table 2 and Table S6). The variance of bacterial community composition between samples was further determined by PCA based on filtered OTU tables. PC1 and PC2 explained more than $40 \%$ of total variation in both cropping seasons. Although the PERANOVA result exhibited a significant difference between bacterial profiles under different field management systems, only a subtle clustering was observed in the PCA plots (Figure S1). We further identified the abundant taxa groups either under conventional or organic farming systems. Patescibacteria at the phylum level and Parcubacteria at the class level were consistently enriched at the tillering stage under the conventional farming system in both seasons, but no taxonomic group was consistently enriched under organic farming systems in both seasons (Figure S2). While only a few taxa consistently responded to field management, we found some genera comprising of the members known as plant growth promoting bacteria (PGPB) enriched in either one of the farming systems. At the tillering stage in the first cropping season, Pseudomonas was abundant under the organic farming system, while Bradyrhizobium and Burkholderia were enriched under the conventional farming system (Figure S3). In the second cropping season, Bacillus and Azospirillum were abundant both at the seedling and tillering stage under the organic farming system, while Bradyrhizobium and Sphingomonas were enriched only at the seedling stage under the conventional farming system (Figure S4).

In addition, we performed a Mantel test to examine the association between the bacterial community composition at the tillering stage and environmental factors. The rho indices of each comparison suggested that in both cropping seasons, the content of organic matter and the ratio of calcium saturation were significantly associated with root microbiota (Table 3). The association of environmental factors with the bacterial community composition at both growth stages was further dissected by CCA, which showed that organic matter content and soil $\mathrm{pH}$ were positively correlated with the microbial profiles derived from organic fields in both cropping seasons. However soil electrical conductivity (EC) was positively and negatively correlated with microbiota derived from organic fields in the first and second season, respectively (Figure 3). This result indicated that soil properties still had some impacts on the root endophytic microbiota. 
Table 2. PERMANOVA results testing the impacts of field management, growth stage, and the interaction between the two factors on rice root endophytic bacterial community composition.

\begin{tabular}{|c|c|c|c|c|c|c|c|c|c|c|}
\hline \multirow{2}{*}{$\begin{array}{c}\text { Cropping Season } \\
\text { Factor }\end{array}$} & \multicolumn{5}{|c|}{ First Cropping Season, 2019} & \multicolumn{5}{|c|}{ Second Cropping Season, 2019} \\
\hline & Df & SS $^{\mathrm{a}}$ & $\mathbf{R}^{2}$ & F & $p^{\mathrm{b}}$ & Df & SS & $\mathbf{R}^{2}$ & F & $p$ \\
\hline Management ${ }^{c}$ & 1 & 0.4158 & 0.0364 & 2.5838 & $0.036^{*}$ & 1 & 0.8762 & 0.1109 & 7.6634 & $<0.001^{* * *}$ \\
\hline Growth stage ${ }^{d}$ & 1 & 4.8445 & 0.4236 & 30.101 & $<0.001^{* * *}$ & 1 & 2.4076 & 0.3048 & 21.058 & $<0.001^{* * *}$ \\
\hline $\begin{array}{l}\text { Management } \times \\
\text { Growth stage }\end{array}$ & 1 & 0.3831 & 0.0335 & 2.3802 & 0.05 & 1 & 0.4994 & 0.0632 & 4.3684 & $0.002 * *$ \\
\hline Residual & 36 & 5.7939 & 0.5066 & & & 36 & 4.1159 & 0.5211 & & \\
\hline Total & 39 & 11.437 & 1 & & & 39 & 7.8992 & 1 & & \\
\hline
\end{tabular}

a SS: Sum of squares; ${ }^{\mathrm{b}}$ significance: ${ }^{* * *} p<0.001 ;{ }^{* *} p<0.01{ }^{*} p<0.05 .{ }^{\mathrm{c}}$ Management: Testing the effects of field management (conventional and organic systems) on rice root microbiota in the corresponding season. ${ }^{\mathrm{d}}$ Growth stage: Testing the effects of growth stages on rice root microbiota in the corresponding season. ${ }^{e}$ Management $\times$ Growth stage: Testing the effects of the interaction between field management and growth stage on rice root microbiota.

Table 3. Evaluation of the effects of soil properties on rice root endophytic bacterial communities at tillering stage using the Mantel test.

\begin{tabular}{ccc}
\hline Soil Properties & Correlation (Rho) ${ }^{\text {a }}$ & $p$-Value \\
\hline \multicolumn{3}{c}{ First cropping season, 2019 } \\
\hline Soil pH & 0.1898 & 0.0012 \\
Organic matter content & 0.3662 & $1 \times 10^{-4}$ \\
Calcium saturation ratio & 0.3743 & $1 \times 10^{-4}$ \\
\hline \multicolumn{3}{c}{ Second cropping season, 2019 } \\
\hline Soil pH & 0.2537 & 0.0016 \\
Organic matter content & 0.3096 & $5 \times 10^{-4}$ \\
Calcium saturation ratio & 0.3329 & 0.0036 \\
\hline The test was performed separately for each season with 9999 permutations.
\end{tabular}

(A)

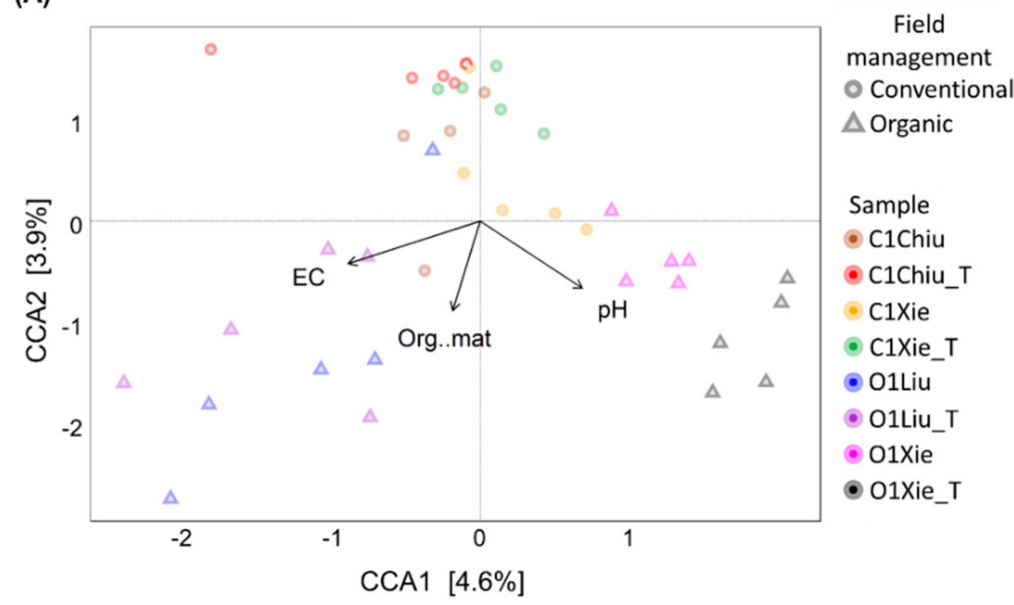

Figure 3. Cont. 
(B)

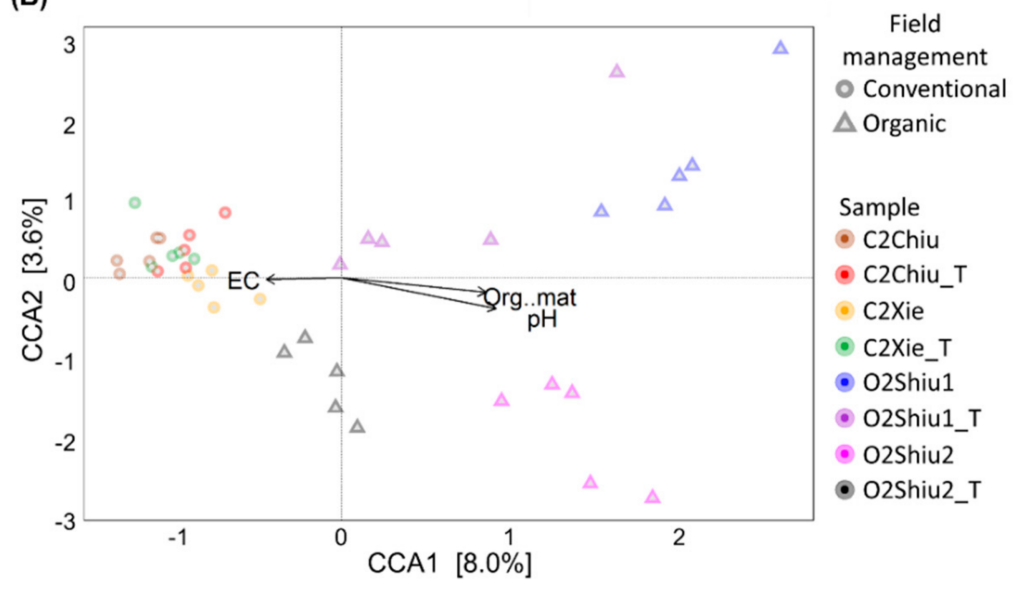

Figure 3. Canonical correspondence analysis (CCA) ordination diagram showing the correlation between rice root bacterial community composition and environmental variables in the first (A) and second (B) cropping season. The data points are colored by samples. The circle and triangle mean the samples from conventional and organic fields, respectively. Only the environmental variables that were statistically significant when assessed by the marginal test are shown. The direction and the length of arrows indicate the steepness increase and strength of variables, compared to others. EC: Soil electrical conductivity; Org.mat: Soil organic matter content; and $\mathrm{pH}$ : Soil $\mathrm{pH}$.

\subsection{The Effects of Growth Stage on Root Microbial Composition}

To examine the effect of growth stage on root microbial profiles, we sampled rice plants at the seedling and tillering stages over two consecutive cropping seasons. Environmental factors such as temperature, rainfall, light intensity, and light period differed greatly among plant growth stage and between seasons (Figure 1). This might have affected plant growth, microbial community composition, and activity in the rhizosphere and roots [46]. Across all samples, $\alpha$-diversity was not significantly affected by growth stage, except for the group sampled in one of the conventional farming system fields. In terms of species richness, evenness, and diversity, plant growth stage and environmental factors were not major determinants. We further analyzed the effects on microbial community composition by using PERMANOVA based on Bray-Curtis distance. In both cropping seasons, growth stage significantly influenced microbial community composition, despite the different field management systems (Table 2 and Table S7). PCA was performed to evaluate factors influencing the variance of bacterial community composition based on filtered OTU tables. In the first and second cropping seasons, $65.8 \%$ and $42.1 \%$ of variance were explained by PC 1 , respectively. The microbial groups were clustered by growth stage and the clearest separation was displayed in the first cropping season (Figure 4).

We further identified OTUs affected by growth stage. Based on the taxonomic group, these OTUs were assigned to eight and 26 families in the first and second cropping seasons, respectively. In the first cropping season, the relative abundance of Veillonellaceae and Paludibacteraceae was higher at the seedling stage than the tillering stage, while Burkholderiaceae, Aeromonadaceae, Rhodocyclaceae, Pleomorphomonadaceae, Enterobacteriaceae, and Chromobacteriaceae were more abundant at the tillering stage (Figure 5A). In the second cropping season, 14 and 12 families were enriched at the seedling and tillering stages, respectively (Figure 5B). Among these families, only Veillonellaceae and Paludibacteraceae were consistently enriched at the seedling stage, while other families were enriched either in one of the seasons or at different stages in different seasons (Figure 5). At the genus level, four and 26 bacterial genera responded to growth stage in the first and second cropping seasons, respectively. Only Burkholderia, Caballeronia, Paraburkholderia, and Pleomorphomona were consistently enriched at the tillering stage in both seasons and their relative abundance was $10-20 \%$ and $1-3 \%$ at the tillering stage in the first and second cropping season, respectively. Some genera comprising PGPB were identified, but their response to 
growth stage was only observed in the second cropping season; for example, Bacillus was enriched at the seedling stage and Bradyrhizobium and Sphingomonas were enriched at the tillering stage (Figure S5). These results indicate the great impact of growth stage on root microbial communities, but the effects of environmental factors varying by season are not negligible.
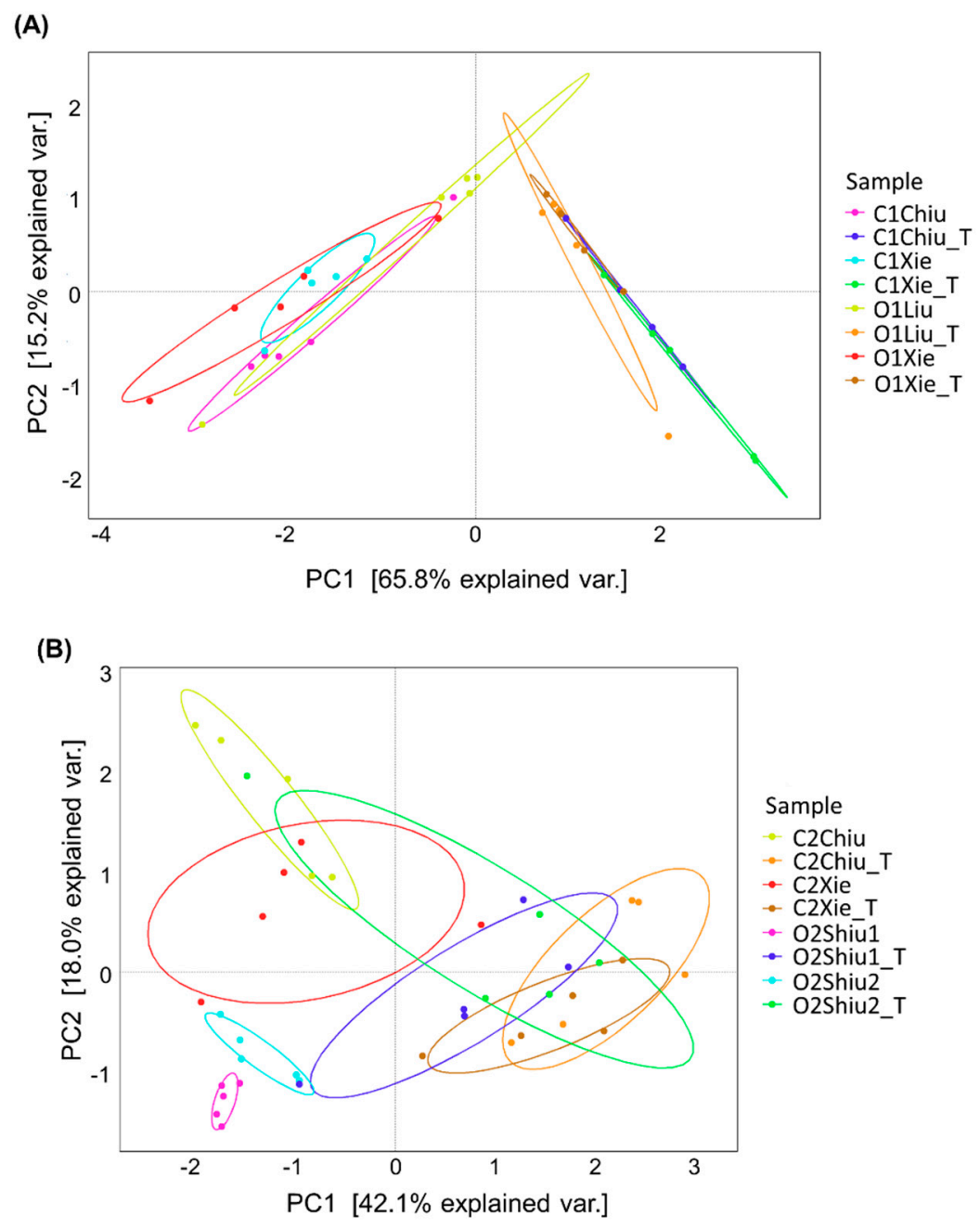

Figure 4. PCA of rice root endophytic bacterial communities based on filtered operational taxonomic units (OTU) tables in the first (A) and second (B) cropping season. The data points are colored by samples.

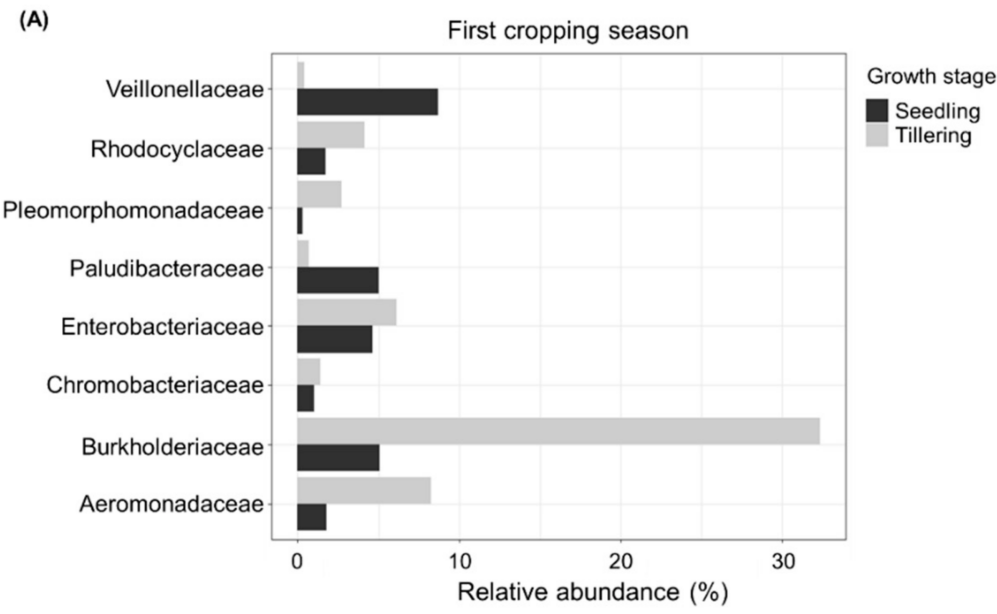

Figure 5. Cont. 


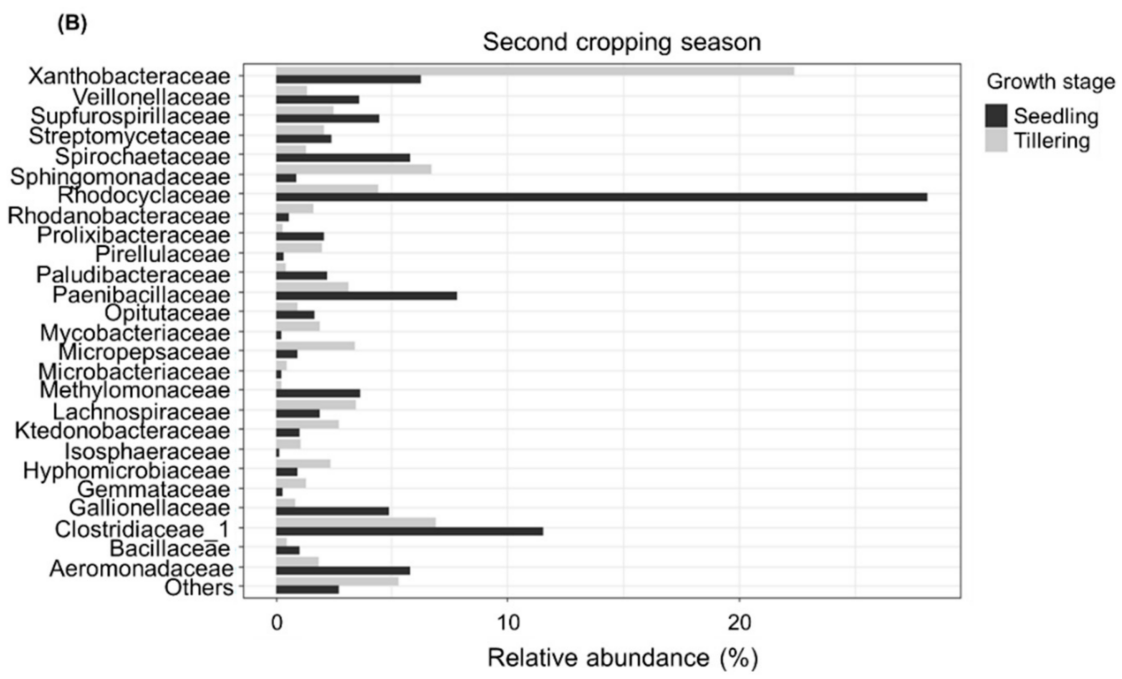

Figure 5. Relative abundance of the bacterial families which were enriched either at the seedling or tillering stage in the first (A) and second (B) cropping season.

The effects of the interaction between farming management system and plant growth stage on bacterial community composition were evaluated using PERMANOVA. Although both field management system and growth stage were critical for the bacterial community structure in both seasons, the effects of management $\times$ growth stage were only statistically significant in the second cropping season (Table 2).

\subsection{Identification of Plant Growth Stage and Field Management System Sensitive OTUs}

To identify OTUs sensitive to the plant growth stage and field management system in rice roots, we employed indicator species analysis to find OTUs that were enriched at either the growth stage or field management system, and validated results with a likelihood ratio test. Consistent with the PCA results, we identified more OTUs sensitive to plant growth stage in the first cropping season (29 OTUs) compared with the second cropping season (11 OTUs) (Figure 6), and the total relative abundance of sensitive OTUs was $35.8 \%$ and $6.81 \%$, respectively. Interestingly, there was one OTU assigned to Bacteroidales, which was an indicator species at the seedling stage and the tillering stage in the first and second cropping seasons, respectively. OTUs that were associated with the organic farming system were only identified in the second cropping season and their total relative abundance was $4.27 \%$. The three OTUs assigned to Enterobacteriaceae, Methylomonas, and Ralstonia pickettii. Interestingly, Ralstonia pickettii was also an indicator species at the tillering stage in the first season (Figure 6). In summary, the indicator species varied by growth stage and cropping season. Long-term studies are required to identify particular taxonomic groups associated with specific plant growth stages and field management systems.

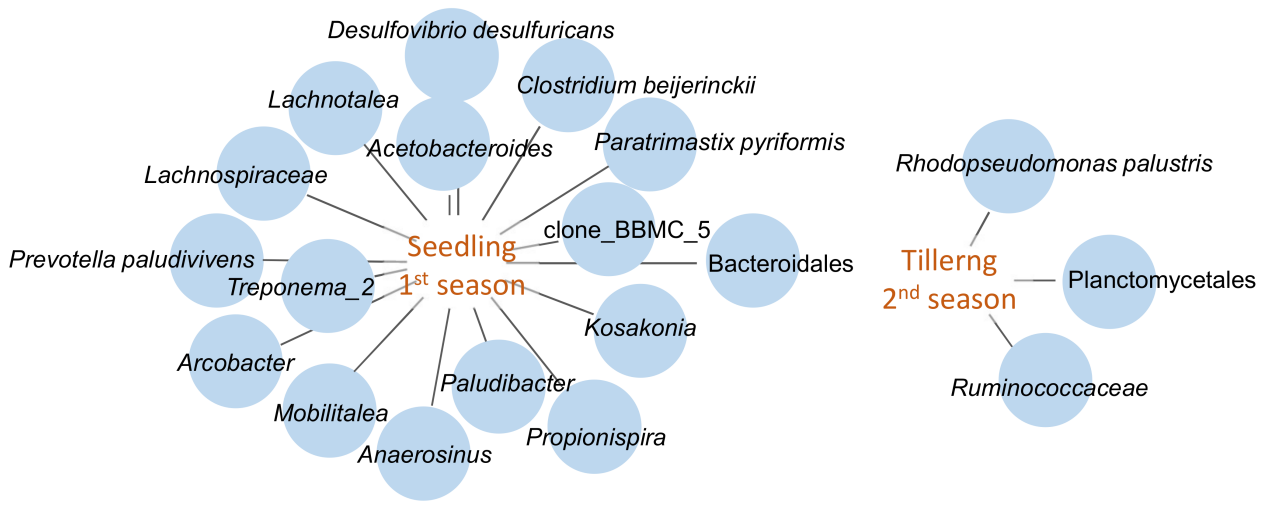

Figure 6. Cont. 


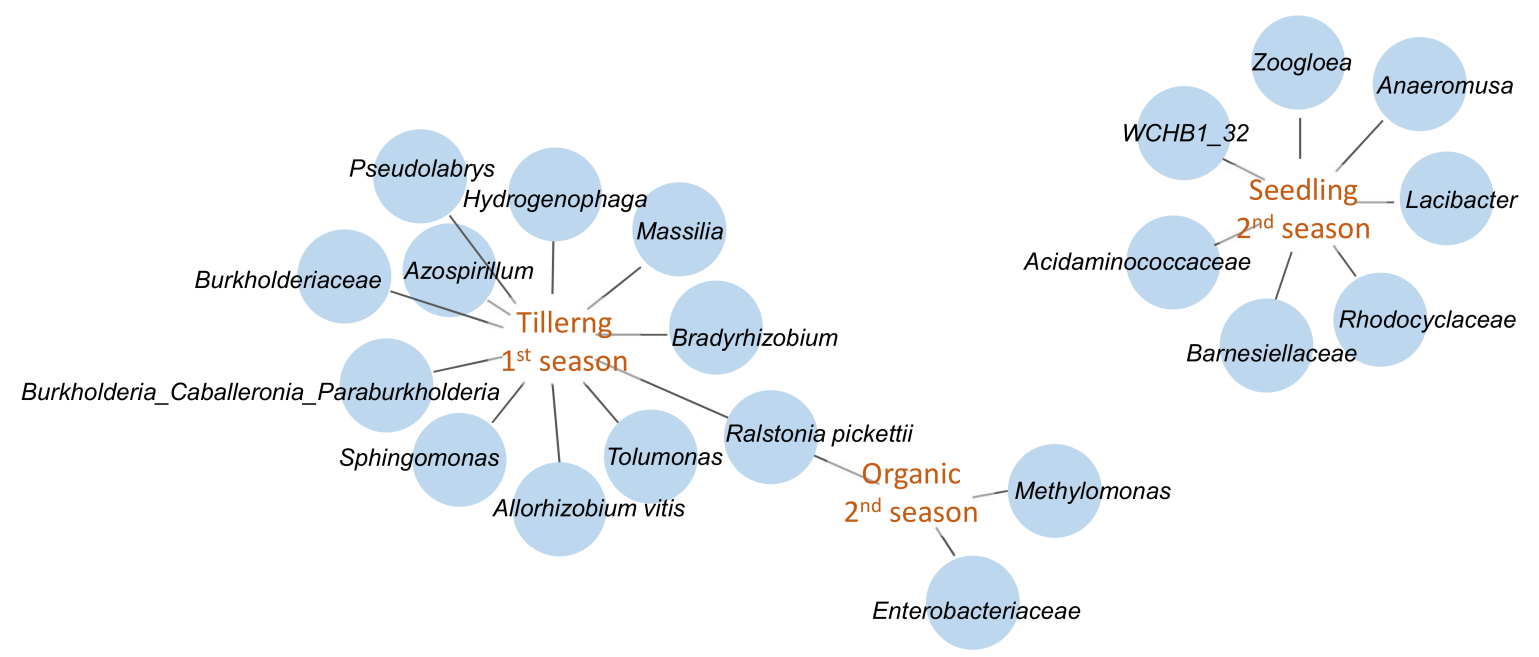

Figure 6. The bipartite network displays OTUs that were sensitive to different plant growth stages. Each circle represents an individual OTU at the taxonomic level that was positively and significantly correlated with the corresponding growth stage or field management system $(p<0.05)$.

\subsection{Functional Prediction of Rice Root Endophytic Bacterial Communities}

The functions of rice root bacterial communities were predicted using the PICRUSt algorithm. Across all samples, the predicted functions which were associated with particular growth stages were assigned to five level 1 KEGG categories. We compared the KEGG category profiles of rice root endophytic bacteria between the two growth stages using PCA based on the relative abundance of each category. In the first cropping season, samples from different growth stages were clearly separated along the axis of PC1, which explained the $50.9 \%$ variation. In the second cropping season, although the difference between samples was not as obvious as it was in the first cropping season, they were still separated along PC1 and PC2, which explained the $35.1 \%$ and $24.1 \%$ variation, respectively (Figure 7). We identified the functional groups of bacterial communities whose relative abundance were higher than $0.5 \%$ and were significantly different between growth stages. We found 55 and 41 third level KEGG categories that were enriched at either the seedling or tillering stage in the first and second cropping season, respectively (Figure 8). There were 34 categories commonly seen in both seasons, but only 13 and two categories were consistently enriched at the seedling and tillering stage, respectively, while others showed the opposite response to growth stage in different seasons. The functional categories consistently enriched at the tillering stage were "tryptophan metabolism" and "glycine, serine and threonine metabolism"; those enriched at the seedling stage included "bacterial chemotaxis", "carbon fixation pathway in prokaryotes", "nitrogen metabolism", "peptidoglycan biosynthesis", "phenylalanine, tyrosine, tryptophan biosynthesis", "other ion-coupled transporters", "translation proteins", and six more functional groups in "genetic information processing", in the level 1 KEGG category.

There were 26 and 44 categories that were enriched under either conventional or organic farming systems in the first and second cropping seasons, respectively. Eight categories were commonly identified in both seasons, but only "nucleotide metabolism", "transcription related proteins", and "glycosphingolipid biosynthesis" were consistently abundant under the organic farming system, and "nitrotoluene degradation" was enriched under the conventional farming system (Figure S6). 
(A)

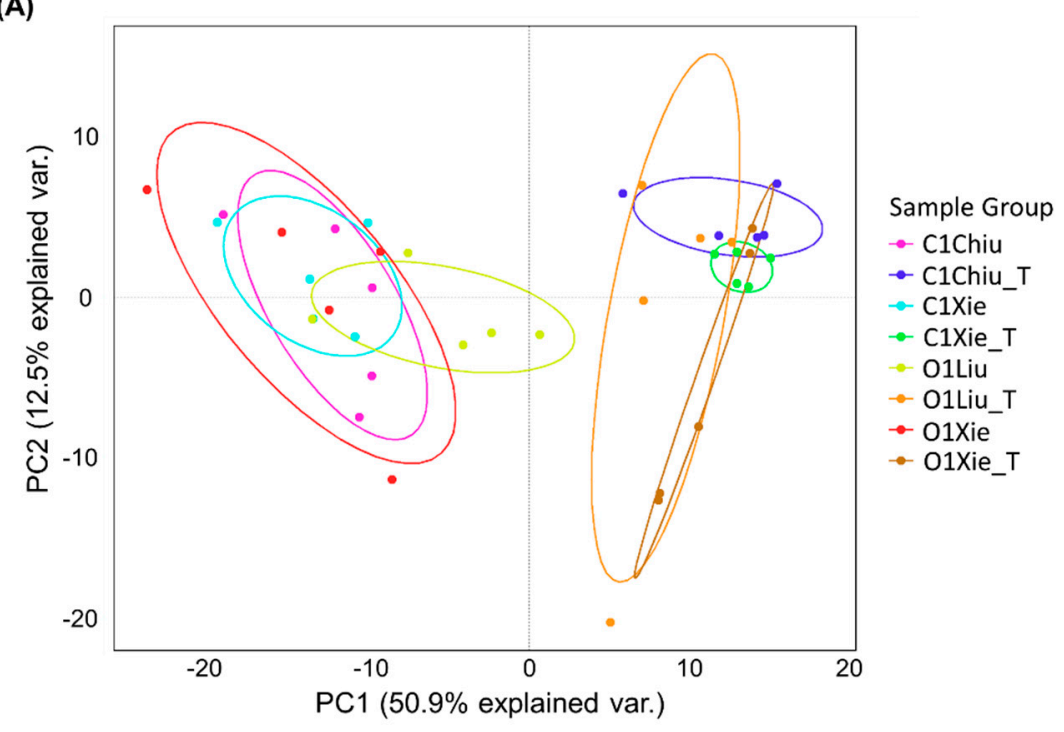

(B)

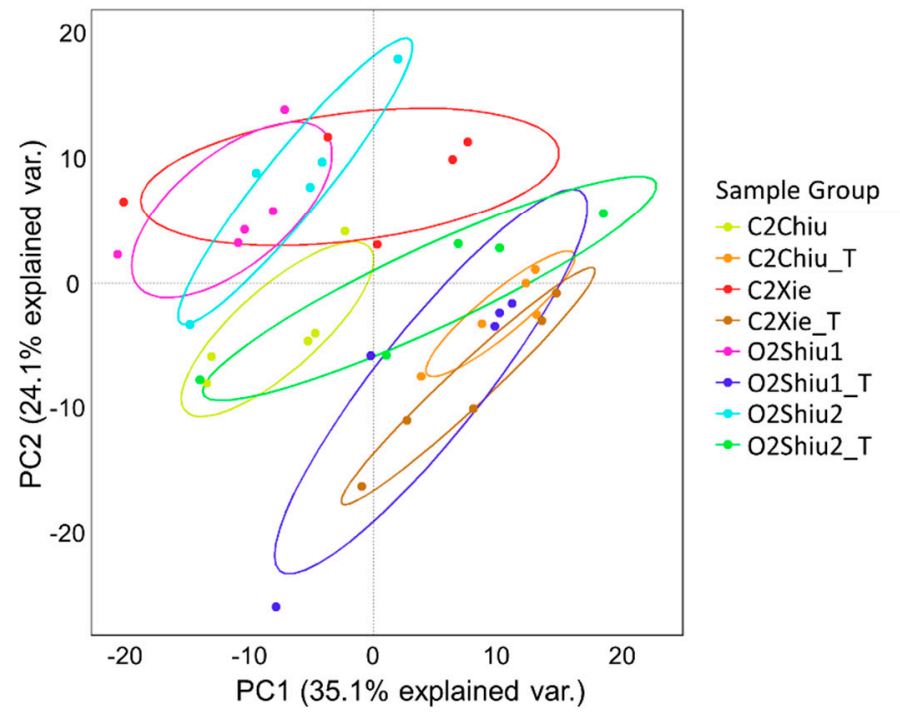

Figure 7. PCA of KEGG category profiles of rice endophytic bacteria which were associated with plant growth stage in the first (A) and second (B) cropping seasons. The data points were colored by sample groups. 
(A)

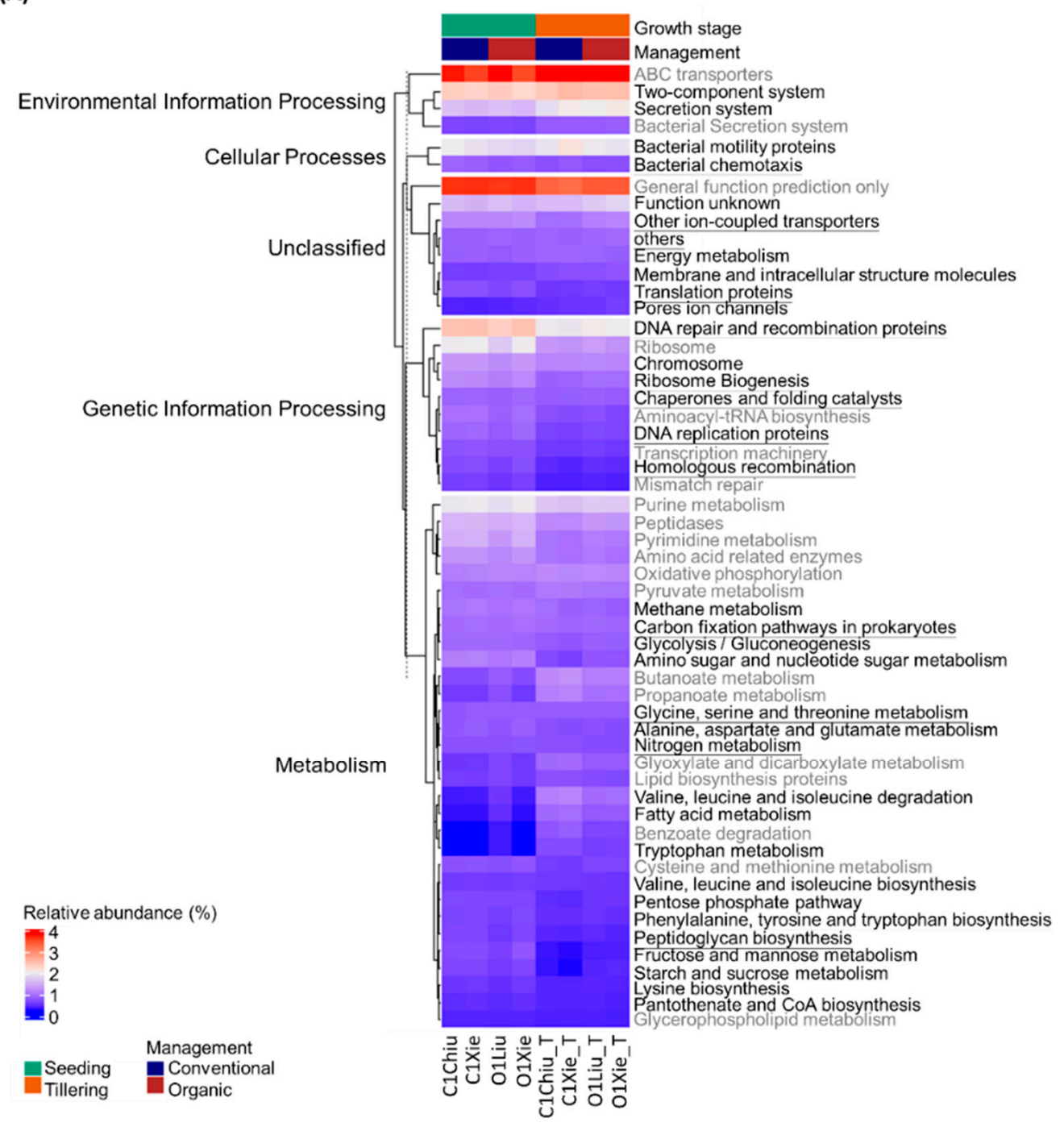

Figure 8. Cont. 
(B)

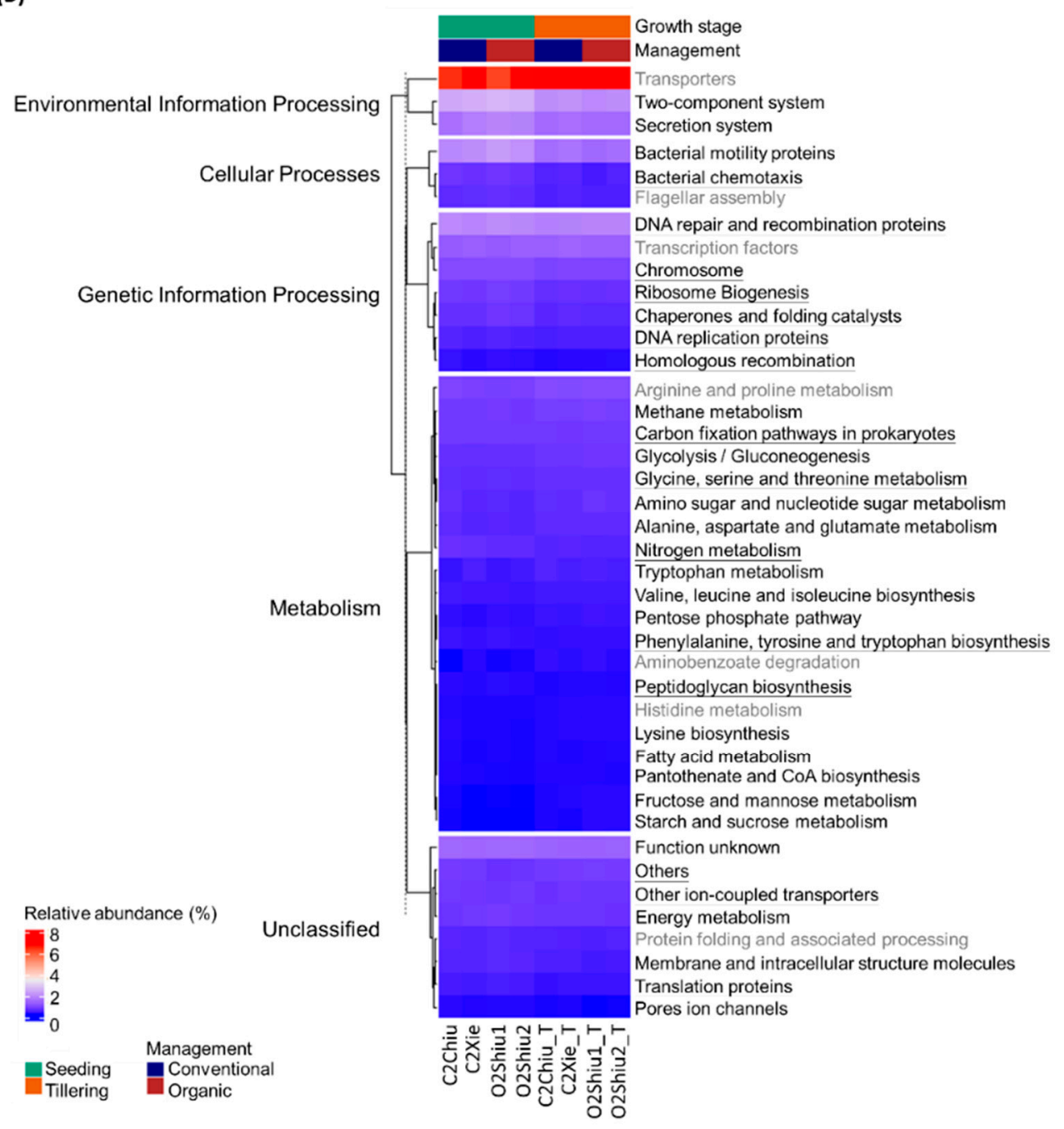

Figure 8. Heat map displaying the third level KEGG categories of rice endophytic bacteria which varied by growth stage in the first (A) and second (B) cropping season. Only functional groups with relative abundance of more than $0.5 \%$ are shown. The categories labeled in gray are the functional groups identified in only one season and the underlined groups are those that exhibited the same response to the plant growth stage in both seasons.

\section{Discussion}

Agriculture practices, such as tillage, irrigation, and fertilization, have great impacts on soil properties and the agricultural ecosystem. Several studies have shown the impacts of agriculture practices and farming systems on the soil, rhizosphere, and root microbiomes, but responses vary by practices used, farming systems, location, and plant species. Hartman et al. [8] demonstrated the differential responses of soil and root bacterial communities to tillage intensities and farming systems: Soil bacterial communities were more sensitive to tillage while root endophytes were strongly influenced by farming systems. Wemheuer et al. [16] displayed the species-specific responses of root endophytic communities to fertilizer application and mowing frequency by comparing the root microbiomes of three grass species. They focused on the effects of agriculture practices and farming systems on root endophytes, but whether these responses change over time during plant growth and development was unclear. Here, we investigated the rice root endophytic bacterial microbiomes under conventional and organic farming systems at the seedling and tillering stage over two consecutive cropping seasons. Each season, 40 samples derived from two conventional and two organic paddy fields were analyzed. 
To our knowledge, this is the first study to evaluate and compare the impacts of field management and growth stage on the root endophytic microbiomes by PCR-based amplicon sequencing.

Consistent with previous studies, agriculture practices and farming systems have marginal or no significant effects on the $\alpha$-diversity of root endophytic communities, but greater impacts on bacterial community structure $[8,16]$. In all of the organic fields included in this study, soil $\mathrm{pH}$ and organic matter content were higher than in conventional fields, and these factors were positively correlated with root bacterial community structure in organic fields (Figure 3), suggesting that the variation of soil properties partially contributes to the root microbiome. Soil pH is known as a key factor determining the soil bacterial community and its functions [47]. The variation of soil bacterial community structure might affect the pool of rhizobacteria, which is one of the sources of root endophytic bacteria. Proteobacteria, Firmicutes, Bacteroidetes, Epsilonbacteraeota, Spirochaetes, and Actinobacteria were the dominant phyla across all samples (Figure 2), which is partly consistent with findings of a previous study on rice and Allium spp. [48,49], but differs to the findings of studies on wheat, tomato, and other grass species $[8,16,50]$, indicating that location and species-specific effects influence bacterial community structure. The differential response of bacterial community composition to field management was primarily observed at the tillering stage in both cropping seasons (Table 2 and Table S6). We identified the taxanomic groups highly associated with field management systems, but only a few responded consistently in both seasons (Figures S2-S4). Among these, Bacillus and Azospirillum were abundant under the organic farming system in the second cropping season and both genera are known for plant growth promoting activity such as nitrogen fixation and phosphate solubility, and for acting as a biocontrol reagent [51,52]. However, the relative abundance of these genera was below $2 \%$. Further studies are needed to clarify the role of these potential PGPBs in rice.

Compared to the farming system, the plant growth stage had a greater impact on rice root bacterial community composition. Our findings mirror those of previous studies, that is, that the effect of growth stage on root microbiomes was more dominant than fertilizer application [33,53]. Dynamics of the rhizosphere and root microbiomes during plant growth and development have been revealed using 16S rRNA gene amplicon-based gel electrophoration and high throughput sequencing [31-33,53,54]. A complete survey of the soil and maize rhizosphere microbiome demonstrated that soil microbiomes are relatively stable and are affected primarily by fields, while rhizosphere microbiomes are similar to soil microbiomes at the early growth stage but then gradually shape the distinct community structure during plant growth [53,54]. The effects of growth stage on the rhizosphere and root microbiome are partially attributed to the dynamics of root exudate composition. It is known that root exudate composition varies by plant species, growth stage, environmental conditions, and other factors $[20,21,24,25,29]$. During plant growth, photosynthetic carbon (C) supports vegetative and reproductive growth at different stages. In rice, the translocation of assimilated $C$ into roots is much more active at the maximum tiller number stages than booting and milking stages to promote root growth and nutrient acquisition. This coincides with the high accumulation of assimilated $\mathrm{C}$ incorporated by soil microorganisms at the maximum tiller number stage, compared to the milking stage [55]. An increase in the carbon source may support a greater number of microorganisms however, in this study we did not see a significant difference in $\alpha$-diversity between the seedling and tillering stages. Due to a preference of metabolites by rhizosphere bacteria, the changes of root exudate composition during plant growth reprogram rhizosphere microbial communities and functions, which are positively correlated with plant physiological demands such as nitrogen uptake and defense system activation $[29,30,53]$. Thus, the variation of root exudate composition by growth stage and plant species drives the distinct structure of rhizosphere microbiomes. The rhizosphere is known as a seed bank of root endophytes. In addition to the selective force in the rhizosphere, bacteria need to pass the barrier of root cells to colonize the endosphere. Comprehensive studies of root and rhizosphere microbiomes among 30 plant species demonstrated that the strength of the barrier differs by plant species. Compared to the rhizosphere microbiome diversity, the structure of the root microbiome is 
primarily determined by the host plant species [56]. We believe that these selective forces partially explain the variation of root microbiomes during plant growth that we found.

In our study, significant differences in root bacterial community composition between the two growth stages were observed in both cropping seasons. At the family level, Veillonellaceae was consistently enriched at the seedling stage, while at the genus level, Burkholderia and Pleomorphomonas were enriched at the tillering stage (Figure 5 and Figure S5). Burkholderia, which are known as PGPB, have nitrogen fixing and phosphorus solubilizing abilities $[57,58]$. In the second cropping season, we observed an increase of Bradyrhizobium and Sphingomonas at the tillering stage. Bradyrhizobium, which are known as nitrogen fixing, phosphorus solubilizing and siderophore producing rhizobacteria [58], had a relative abundance of more than $5 \%$ in rice root endophytic bacteria. The plant growth promoting activities of Sphingomonas were also demonstrated in recent papers [59-61]. It is possible that plants attract more beneficial bacteria as plant growth progresses and selectively allow them to colonize the roots to benefit plant health and development.

We also identified OTUs that are sensitive to variables by indicator species analysis. Among the sensitive taxa groups, Paludibacter, Rhodocyclaceae, and WCHB1 32 were relatively abundant at the seedling stage, while Burkholderia_Caballeronia_Paraburkholderia, Burkhoderiaceae, and Planctomycetales were more abundant at the tillering stage (Figure 6). These abundant sensitive taxa may have important roles in plant physiology and crop ecology. Thus, further characterization will be required to reveal their functions by metagenome and transcriptome analyses.

Similar to the clear separation of rice root bacterial community composition by growth stage, the predicted functional category profiles also responded to the growth stage. Across two seasons, the relative abundance of 15 KEGG level three functional categories were consistently associated with certain growth stages. At the seedling stage, the functional categories "nitrogen metabolism", "other ion-coupled transporters", and "bacterial chemotaxis" were more abundant (Figure 8). Bacterial chemotaxis is important for bacteria to enable movement along nutrient gradients and to colonize nutrient-rich environments, such as the rhizosphere and roots [62]. The enrichment of these functions suggested that, at the early growth stage, rice roots actively recruit bacteria to enhance nutrient uptake and metabolism. At the tillering stage, the relative abundance of tryptophan metabolism was higher than during the seedling stage (Figure 8). Tryptophan is the precursor of indoleacetic acid (IAA) and the application of tryptophan enhances the nutrient uptake and growth of PGPB-inoculated plants [63]. The genus Bradyrhizobium was also more abundant at the tillering stage, and this can synthesize IAA using tryptophan as a precursor $[64,65]$. Thus, at the tillering stage rice preferentially selects beneficial microbes to colonize it and promote plant growth and tiller production.

About $50 \%$ of the variation in bacterial community composition was explained by the plant growth stage and farming system. The rice cultivar used and local environmental conditions are possibly involved in shaping the structure of root bacterial communities. The influence of crop genotype on the rhizosphere and root endophytic bacterial community composition has been discussed. For example, in Japonica rice (Oryza sativa) and African rice (Oryza glaberrima), the rhizosphere microbiomes are clearly separated, while for Indica rice cultivars (Oryza sativa), some are close to those in Japonica rice and some are close to African rice [48]. The effect of host species identity on the rhizosphere microbiome has been found in Mimulus guttatus ecotypes and maize cultivars [66,67], but evidence shows that the effect of genotype on root endophytic microbiome is relatively marginal $[48,54,66]$. In this study, although the rice cultivars in conventional and organic fields differed, they all belong to the Japonica type. Moreover, the two conventional fields in both seasons were planted with the same cultivar, but we still observed a difference in the root bacterial structure between growth stages, suggesting that the effect of the growth stage is the major driving force shaping the root microbiome, while the effect of genotype is relatively small.

We also found a seasonal difference in the root microbiome. In the first cropping season, the monthly maximum temperature in the sampling period (February-April) was lower than in the second season (August-September). Monthly rainfall gradually increased in the first season 
while it was extremely high at the seedling stage compared to the tillering stage in the second season (Figure 1). The difference in weather conditions means that photosynthesis, nutrient uptake efficiency, and metabolism in rice plants and the biochemical responses of microorganisms were probably affected, leading to differing microbiome structure. Walters et al. [54] also pointed out the impacts of weather and identified several bacterial families in the rhizosphere which positively or negatively responded to weather conditions. Longer term and larger scale studies are required to reveal the impacts of weather on root endophytic bacteria.

In summary, we investigated the rice root endophytic microbiome in conventional and organic paddy fields at the seedling and tillering growth stages over two consecutive cropping seasons. Our study showed the significant effects of the plant growth stage, field management system, and the interaction between these two factors on rice root endophytic bacterial community composition but not on their $\alpha$-diversity. Among these factors, growth stage played the most important role in shaping the root microbiome. We also found that soil $\mathrm{pH}$ and organic matter content influenced the root microbiome. Additionally, we identified potential indicator species in response to plant growth stage and field management system. This study demonstrated the dynamics of the rice root microbiome under different farming systems over time, providing new insights for microbiome management. Further studies are required to reveal and manipulate the functions of the microbiome to improve the sustainability of the agriculture system.

Supplementary Materials: The following are available online at http://www.mdpi.com/2073-4395/10/11/1623/s1. Table S1: Information about experimental fields. Table S2: Soil properties of sampling fields. Table S3: 16S rRNA gene sequencing results. Table S4: PERMANOVA testing the effect size between samples. Table S5: Alpha diversity indices of rice root endophytic bacteria. Table S6: PERMANOVA results testing the association of field management system with bacterial community structure. Table S7: PERMANOVA results testing the association of growth stage with bacterial community structure. Figure S1: PCA of rice root bacterial profiles at the seedling (A and C) and tillering (B and D) stages based on filtered OTU tables. Figure S2: The taxa groups at phylum and class level consistently enriched in rice roots under conventional farming systems at the tillering stage in the first (A and C) and second (B and D) cropping seasons. Figure S3: The genera comprising members known as PGPBs were significantly abundant in rice roots under conventional farming systems (A and B) or organic (C) farming systems at tillering stage in the first cropping season. Figure S4: The genera comprising members known as PGPBs were significantly abundant in rice roots under organic farming systems (A and B) both at seedling and tillering stages or only under conventional farming systems at seedling stage $(C$ and $D)$ in the second cropping season. Figure S5: Relative abundance of genera which differed significantly in abundance between plant growth stages in the first (A) and second (B) cropping seasons. Figure S6: Heat map displaying the third level KEGG categories of rice endophytic bacteria which differed significantly by field management system in the first (A) and second (B) cropping seasons.

Author Contributions: Conceptualization, W.-Y.L. and S.-J.C.; methodology, W.-Y.L.; formal analysis, G.-Y.L.; investigation, G.-Y.L. and C.-Y.L.; resources, C.-Y.L.; writing-Original draft preparation, W.-Y.L. and G.-Y.L.; writing-Review and editing, W.-Y.L.; visualization, G.-Y.L. and W.-Y.L.; supervision, W.-Y.L.; project administration, W.-Y.L.; funding acquisition, W.-Y.L. All authors have read and agreed to the published version of the manuscript.

Funding: This research was funded by the Department of Science and Technology at the Council of Agriculture, Executive Yuan, Taiwan, China.

Acknowledgments: We thank colleagues from the Miaoli District Agricultural Research and Extension Station for their support with soil property analysis and Biotools Co., Ltd. for technical support with sequencing and data analysis.

Conflicts of Interest: The authors declare no conflict of interest. The funders had no role in the design of the study; in the collection, analyses, or interpretation of data; in the writing of the manuscript, or in the decision to publish the results.

\section{References}

1. Tilman, D. Global environmental impacts of agricultural expansion: The need for sustainable and efficient practices. Proc. Natl. Acad. Sci. USA 1999, 96, 5995-6000. [CrossRef] [PubMed]

2. Pimentel, D.; Hepperly, P.; Hanson, J.; Douds, D.; Seidel, R. Environmental, energetic, and economic comparisons of organic and conventional farming systems. Bioscience 2005, 55, 573-582. [CrossRef] 
3. Reganold, J.P.; Elliott, L.F.; Unger, Y.L. Long-term effects of organic and conventional farming on soil-erosion. Nature 1987, 330, 370-372. [CrossRef]

4. Wood, R.; Lenzen, M.; Dey, C.; Lundie, S. A comparative study of some environmental impacts of conventional and organic farming in Australia. Agric. Syst. 2006, 89, 324-348. [CrossRef]

5. Tal, A. Making conventional agriculture environmentally friendly: Moving beyond the glorification of organic agriculture and the demonization of conventional agriculture. Sustainability 2018, 10, 1078. [CrossRef]

6. Mader, P.; Fliessbach, A.; Dubois, D.; Gunst, L.; Fried, P.; Niggli, U. Soil fertility and biodiversity in organic farming. Science 2002, 296, 1694-1697. [CrossRef]

7. Chávez-Romero, Y.; Navarro-Noya, Y.E.; Reynoso-Martínez, S.C.; Sarria-Guzmán, Y.; Govaerts, B.; Verhulst, N.; Dendooven, L.; Luna-Guido, M. 16S metagenomics reveals changes in the soil bacterial community driven by soil organic C, N-fertilizer and tillage-crop residue management. Soil Tillage Res. 2016, 159, 1-8. [CrossRef]

8. Hartman, K.; van der Heijden, M.G.A.; Wittwer, R.A.; Banerjee, S.; Walser, J.-C.; Schlaeppi, K. Cropping practices manipulate abundance patterns of root and soil microbiome members paving the way to smart farming. Microbiome 2018, 6, 14. [CrossRef]

9. Wang, J.J.; Li, X.Y.; Zhu, A.N.; Zhang, X.K.; Zhang, H.W.; Liang, W.J. Effects of tillage and residue management on soil microbial communities in North China. Plant Soil Environ. 2012, 58, 28-33. [CrossRef]

10. Benitez, M.S.; Osborne, S.L.; Lehman, R.M. Previous crop and rotation history effects on maize seedling health and associated rhizosphere microbiome. Sci. Rep. 2017, 7, 15709. [CrossRef]

11. Morrison-Whittle, P.; Lee, S.A.; Goddard, M.R. Fungal communities are differentially affected by conventional and biodynamic agricultural management approaches in vineyard ecosystems. Agric. Ecosyst. Environ. 2017, 246, 306-313. [CrossRef]

12. Esperschutz, J.; Gattinger, A.; Mader, P.; Schloter, M.; Fliessbach, A. Response of soil microbial biomass and community structures to conventional and organic farming systems under identical crop rotations. FEMS Microbiol. Ecol. 2007, 61, 26-37. [CrossRef] [PubMed]

13. Chanway, C. Endophytes: They're not just fungi! Can. J. Plant Sci. 1996, 74, 321-322. [CrossRef]

14. Hallmann, J.; QuadtHallmann, A.; Mahaffee, W.F.; Kloepper, J.W. Bacterial endophytes in agricultural crops. Can. J. Plant Sci. 1997, 43, 895-914. [CrossRef]

15. Xia, Y.; DeBolt, S.; Dreyer, J.; Scott, D.; Williams, M.A. Characterization of culturable bacterial endophytes and their capacity to promote plant growth from plants grown using organic or conventional practices. Front. Plant Sci. 2015, 6, 490. [CrossRef] [PubMed]

16. Wemheuer, F.; Kaiser, K.; Karlovsky, P.; Daniel, R.; Vidal, S.; Wemheuer, B. Bacterial endophyte communities of three agricultural important grass species differ in their response towards management regimes. Sci. Rep. 2017, 7, 40914. [CrossRef] [PubMed]

17. Bulgarelli, D.; Schlaeppi, K.; Spaepen, S.; van Themaat, E.V.L.; Schulze-Lefert, P. Structure and functions of the bacterial microbiota of plants. Annu. Rev. Plant Biol. 2013, 64, 807-838. [CrossRef]

18. Chi, F.; Shen, S.H.; Cheng, H.P.; Jing, Y.X.; Yanni, Y.G.; Dazzo, F.B. Ascending migration of endophytic rhizobia, from roots to leaves, inside rice plants and assessment of benefits to rice growth physiology. Appl. Environ. Microbiol. 2005, 71,7271-7278. [CrossRef]

19. Hardoim, P.R.; van Overbeek, L.S.; Elsas, J.D. Properties of bacterial endophytes and their proposed role in plant growth. Trends Microbiol. 2008, 16, 463-471. [CrossRef]

20. Bais, H.P.; Weir, T.L.; Perry, L.G.; Gilroy, S.; Vivanco, J.M. The role of root exudates in rhizosphere interactions with plants and other organisms. Annu. Rev. Plant Biol. 2006, 57, 233-266. [CrossRef]

21. Badri, D.V.; Vivanco, J.M. Regulation and function of root exudates. Plant Cell Environ. 2009, 32, 666-681. [CrossRef] [PubMed]

22. Aulakh, M.S.; Wassmann, R.; Bueno, C.; Kreuzwieser, J.; Rennenberg, H. Characterization of root exudates at different growth stages of ten rice (Oryza sativa L.) cultivars. Plant Biol. 2001, 3, 139-148. [CrossRef]

23. Baetz, U.; Martinoia, E. Root exudates: The hidden part of plant defense. Trends Plant Sci. 2014, 19, 90-98. [CrossRef]

24. Iannucci, A.; Fragasso, M.; Platani, C.; Papa, R. Plant growth and phenolic compounds in the rhizosphere soil of wild oat (Avena fatua L.). Front. Plant Sci. 2013, 4, 509. [CrossRef] 
25. Zhalnina, K.; Louie, K.B.; Hao, Z.; Mansoori, N.; da Rocha, U.N.; Shi, S.; Cho, H.; Karaoz, U.; Loque, D.; Bowen, B.P.; et al. Dynamic root exudate chemistry and microbial substrate preferences drive patterns in rhizosphere microbial community assembly. Nat. Microbiol. 2018, 3, 470-480. [CrossRef]

26. Baudoin, E.; Benizri, E.; Guckert, A. Impact of growth stage on the bacterial community structure along maize roots, as determined by metabolic and genetic fingerprinting. Appl. Soil Ecol. 2002, 19, 135-145. [CrossRef]

27. Mougel, C.; Offre, P.; Ranjard, L.; Corberand, T.; Gamalero, E.; Robin, C.; Lemanceau, P. Dynamic of the genetic structure of bacterial and fungal communities at different developmental stages of Medicago truncatula Gaertn. cv. Jemalong line J5. New Phytol. 2006, 170, 165-175. [CrossRef]

28. Houlden, A.; Timms-Wilson, T.M.; Day, M.J.; Bailey, M.J. Influence of plant developmental stage on microbial community structure and activity in the rhizosphere of three field crops. FEMS Microbiol. Ecol. 2008, 65, 193-201. [CrossRef] [PubMed]

29. Chaparro, J.M.; Badri, D.V.; Bakker, M.G.; Sugiyama, A.; Manter, D.K.; Vivanco, J.M. Root exudation of phytochemicals in Arabidopsis follows specific patterns that are developmentally programmed and correlate with soil microbial functions. PLoS ONE 2013, 8, e55731. [CrossRef]

30. Chaparro, J.M.; Badri, D.V.; Vivanco, J.M. Rhizosphere microbiome assemblage is affected by plant development. ISME J. 2014, 8, 790-803. [CrossRef]

31. Marag, P.S.; Suman, A. Growth stage and tissue specific colonization of endophytic bacteria having plant growth promoting traits in hybrid and composite maize (Zea mays L.). Microbiol. Res. 2018, 214, 101-113. [CrossRef] [PubMed]

32. Marques, J.M.; da Silva, T.F.; Vollú, R.E.; de Lacerda, J.R.M.; Blank, A.F.; Smalla, K.; Seldin, L. Bacterial endophytes of sweet potato tuberous roots affected by the plant genotype and growth stage. Appl. Soil Ecol. 2015, 96, 273-281. [CrossRef]

33. Roesti, D.; Gaur, R.; Johri, B.; Imfeld, G.; Sharma, S.; Kawaljeet, K.; Aragno, M. Plant growth stage, fertiliser management and bio-inoculation of arbuscular mycorrhizal fungi and plant growth promoting rhizobacteria affect the rhizobacterial community structure in rain-fed wheat fields. Soil Biol. Biochem. 2006, 38, 1111-1120. [CrossRef]

34. Robinson, R.J.; Fraaije, B.A.; Clark, I.M.; Jackson, R.W.; Hirsch, P.R.; Mauchline, T.H. Endophytic bacterial community composition in wheat (Triticum aestivum) is determined by plant tissue type, developmental stage and soil nutrient availability. Plant Soil 2015, 405, 381-396. [CrossRef]

35. Caporaso, J.G.; Kuczynski, J.; Stombaugh, J.; Bittinger, K.; Bushman, F.D.; Costello, E.K.; Fierer, N.; Pena, A.G.; Goodrich, J.K.; Gordon, J.I.; et al. QIIME allows analysis of high-throughput community sequencing data. Nat. Methods 2010, 7, 335-336. [CrossRef]

36. Magoc, T.; Salzberg, S.L. FLASH: Fast length adjustment of short reads to improve genome assemblies. Bioinformatics 2011, 27, 2957-2963. [CrossRef]

37. Edgar, R.C. UPARSE: Highly accurate OTU sequences from microbial amplicon reads. Nat. Methods 2013, 10, 996-998. [CrossRef]

38. Edgar, R.C. Search and clustering orders of magnitude faster than BLAST. Bioinformatics 2010, 26, $2460-2461$. [CrossRef]

39. Quast, C.; Pruesse, E.; Yilmaz, P.; Gerken, J.; Schweer, T.; Yarza, P.; Peplies, J.; Glockner, F.O. The SILVA ribosomal RNA gene database project: Improved data processing and web-based tools. Nucleic Acids Res. 2013, 41, D590-D596. [CrossRef]

40. Whittaker, R.H. Evolution and measurement of species diversity. Taxon 1972, 21, 213-251. [CrossRef]

41. Anderson, M.J. A new method for non-parametric multivariate analysis of variance. Austral. Ecol. 2001, 26, 32-46. [CrossRef]

42. Langille, M.G.I.; Zaneveld, J.; Caporaso, J.G.; McDonald, D.; Knights, D.; Reyes, J.A.; Clemente, J.C.; Burkepile, D.E.; Thurber, R.L.V.; Knight, R.; et al. Predictive functional profiling of microbial communities using 16S rRNA marker gene sequences. Nat. Biotechnol. 2013, 31, 814-821. [CrossRef]

43. DeSantis, T.Z.; Hugenholtz, P.; Larsen, N.; Rojas, M.; Brodie, E.L.; Keller, K.; Huber, T.; Dalevi, D.; Hu, P.; Andersen, G.L. Greengenes, a chimera-checked 16S rRNA gene database and workbench compatible with ARB. Appl. Environ. Microbiol. 2006, 72, 5069-5072. [CrossRef] [PubMed]

44. Kanehisa, M.; Goto, S.; Sato, Y.; Furumichi, M.; Tanabe, M. KEGG for integration and interpretation of large-scale molecular data sets. Nucleic Acids Res. 2012, 40, D109-D114. [CrossRef] 
45. Parks, D.H.; Tyson, G.W.; Hugenholtz, P.; Beiko, R.G. STAMP: Statistical analysis of taxonomic and functional profiles. Bioinformatics 2014, 30, 3123-3124. [CrossRef]

46. Ortiz, Y.; Restrepo, C.; Vilanova-Cuevas, B.; Santiago-Valentin, E.; Tringe, S.G.; Godoy-Vitorino, F. Geology and climate influence rhizobiome composition of the phenotypically diverse tropical tree Tabebuia heterophylla. PLoS ONE 2020, 15, e0231083. [CrossRef] [PubMed]

47. Wang, C.-Y.; Zhou, X.; Guo, D.; Zhao, J.-H.; Yan, L.; Feng, G.-Z.; Gao, Q.; Yu, H.; Zhao, L.-P. Soil pH is the primary factor driving the distribution and function of microorganisms in farmland soils in northeastern China. Ann. Microbiol. 2019, 69, 1461-1473. [CrossRef]

48. Edwards, J.; Johnson, C.; Santos-Medellin, C.; Lurie, E.; Podishetty, N.K.; Bhatnagar, S.; Eisen, J.A.; Sundaresan, V. Structure, variation, and assembly of the root-associated microbiomes of rice. Proc. Natl. Acad. Sci. USA 2015, 112, E911-E920. [CrossRef]

49. Huang, Y. Illumina-based analysis of endophytic bacterial diversity of four Allium species. Sci. Rep. 2019, 9, 15271. [CrossRef]

50. Tian, B.Y.; Cao, Y.; Zhang, K.Q. Metagenomic insights into communities, functions of endophytes, and their associates with infection by root-knot nematode, Meloidogyne incognita, in tomato roots. Sci. Rep. 2015, 5, 17087. [CrossRef]

51. Bhattacharyya, P.N.; Jha, D.K. Plant growth-promoting rhizobacteria (PGPR): Emergence in agriculture. World J. Microbiol. Biotechnol. 2012, 28, 1327-1350. [CrossRef]

52. Radhakrishnan, R.; Hashem, A.; Abd Allah, E.F. Bacillus: A biological tool for crop improvement through bio-molecular changes in adverse environments. Front. Physiol. 2017, 8, 667. [CrossRef]

53. Emmett, B.D.; Buckley, D.H.; Drinkwater, L.E. Plant growth rate and nitrogen uptake shape rhizosphere bacterial community composition and activity in an agricultural field. New Phytol. 2020, 225, 960-973. [CrossRef]

54. Walters, W.A.; Jin, Z.; Youngblut, N.; Wallace, J.G.; Sutter, J.; Zhang, W.; Gonzalez-Pena, A.; Peiffer, J.; Koren, O.; Shi, Q.; et al. Large-scale replicated field study of maize rhizosphere identifies heritable microbes. Proc. Natl. Acad. Sci. USA 2018, 115, 7368-7373. [CrossRef]

55. Watanabe, A.; Machida, N.; Takahashi, K.; Kitamura, S.; Kimura, M. Flow of photosynthesized carbon from rice plants into the paddy soil ecosystem at different stages of rice growth. Plant Soil 2004, 258, 151-160. [CrossRef]

56. Fitzpatrick, C.R.; Copeland, J.; Wang, P.W.; Guttman, D.S.; Kotanen, P.M.; Johnson, M.T.J. Assembly and ecological function of the root microbiome across angiosperm plant species. Proc. Natl. Acad. Sci. USA 2018, 115, E1157-E1165. [CrossRef]

57. Estrada-De los Santos, P.; Bustillos-Cristales, R.; Caballero-Mellado, J. Burkholderia, a genus rich in plant-associated nitrogen fixers with wide environmental and geographic distribution. Appl. Environ. Microbiol. 2001, 67, 2790-2798. [CrossRef]

58. Backer, R.; Rokem, J.S.; Ilangumaran, G.; Lamont, J.; Praslickova, D.; Ricci, E.; Subramanian, S.; Smith, D.L. Plant growth-promoting rhizobacteria: Context, mechanisms of action, and roadmap to commercialization of biostimulants for sustainable agriculture. Front. Plant Sci. 2018, 9, 1473. [CrossRef]

59. Khan, A.L.; Waqas, M.; Kang, S.M.; Al-Harrasi, A.; Hussain, J.; Al-Rawahi, A.; Al-Khiziri, S.; Ullah, I.; Ali, L.; Jung, H.Y.; et al. Bacterial endophyte Sphingomonas sp. LK11 produces gibberellins and IAA and promotes tomato plant growth. J. Microbiol. 2014, 52, 689-695. [CrossRef]

60. Pan, F.S.; Meng, Q.; Wang, Q.; Luo, S.; Chen, B.; Khan, K.Y.; Yang, X.E.; Feng, Y. Endophytic bacterium Sphingomonas SaMR12 promotes cadmium accumulation by increasing glutathione biosynthesis in Sedum alfredii Hance. Chemosphere 2016, 154, 358-366. [CrossRef]

61. Luo, Y.; Wang, F.; Huang, Y.L.; Zhou, M.; Gao, J.L.; Yan, T.Z.; Sheng, H.M.; An, L.Z. Sphingomonas sp. Cra20 increases plant growth rate and alters rhizosphere microbial community structure of Arabidopsis thaliana under drought stress. Front. Microbiol. 2019, 10, 1221. [CrossRef]

62. Scharf, B.E.; Hynes, M.F.; Alexandre, G.M. Chemotaxis signaling systems in model beneficial plant-bacteria associations. Plant Mol. Biol. 2016, 90, 549-559. [CrossRef] [PubMed]

63. Hassan, T.U.; Bano, A. The stimulatory effects of L-tryptophan and plant growth promoting rhizobacteria (PGPR) on soil health and physiology of wheat. J. Soil Sci. Plant Nutr. 2015, 15, 190-201. [CrossRef] 
64. Sekine, M.; Ichikawa, T.; Kuga, N.; Kobayashi, M.; Sakurai, A.; Syono, K. Detection of the IAA biosynthetic-pathway from tryptophan via indole-3-acetamide in Bradyrhizobium spp. Plant Cell Physiol. 1988, 29, 867-874. [CrossRef]

65. Wahyudi, A. Production of IAA by Bradyrhizobium sp. WASET 2013, 74, 152-155.

66. Gomes, E.A.; Lana, U.G.P.; Quensen, J.F.; de Sousa, S.M.; Oliveira, C.A.; Guo, J.; Guimarães, L.J.M.; Tiedje, J.M. Root-associated microbiome of maize genotypes with contrasting phosphorus use efficiency. Phytobiomes 2018, 2, 129-137. [CrossRef]

67. Bowsher, A.W.; Kearns, P.J.; Popovic, D.; Lowry, D.B.; Shade, A. Locally adapted Mimulus ecotypes differentially impact rhizosphere bacterial and archaeal communities in an environment-dependent manner. Phytobiomes 2020, 4, 53-63. [CrossRef]

Publisher's Note: MDPI stays neutral with regard to jurisdictional claims in published maps and institutional affiliations.

(C) 2020 by the authors. Licensee MDPI, Basel, Switzerland. This article is an open access article distributed under the terms and conditions of the Creative Commons Attribution (CC BY) license (http://creativecommons.org/licenses/by/4.0/). 